\title{
Interview: Lonnie Thompson
}

\author{
Glaciologist Lonnie Thompson has spent more time above 20,000 feet than any other human \\ being. In collecting a vast library of ice samples from mountain peaks, he has developed a \\ unique view of past and present-day climate change. Anna Barnett caught up with him at \\ the American Geophysical Union's Chapman Conference on Abrupt Climate Change, held \\ 15-19 June at Thompson's own Ohio State University.
}

\section{Why hold a conference on abrupt climate change?}

Understanding the mechanisms of abrupt changes in our climate would be important in any period of time. But in today's world, it's especially important given that we've never had 6.7 billion people before, and that the potential impacts of changes on social and economic systems could be substantial.

\section{Why focus on the past?}

To understand the mechanisms of abrupt changes in the present and future, you need to know what has occurred in the past. We're fortunate to live on a planet that has recorded very detailed histories, often annually, of how the climate system worked in the past. We can look at the various recorders we have, be they ice cores or trees, and learn from them to better understand where we are today and where we may be in the future.

\section{What information can you garner from glaciers?}

Glaciers are like sentinels, and they're telling us that the system is changing. The first thing we look for in the ice is radioactivity from thermonuclear bomb tests in 1962-1963 and 1951-1952. Back in 2006, we drilled three cores in the southwestern Himalayas. At 6,050 metres, where those glaciers reach their highest elevation, we found that neither of these radioactive layers was preserved. The glaciers are being decapitated. Not only are they retreating up the mountain slopes, but they are thinning from the top down.

This same scenario is playing out on Mount Kilimanjaro in Africa. When we drilled there in 2000 we found the 1951 test preserved, but not the 1962 test. We've since continued to monitor those glaciers and we know that we've lost three metres of ice since 2000. If we had waited until this year to drill, we would not have found the 1951 bomb horizon, because that has now been lost.

What does that mean for climate science? Once a glacier melts, the history it contained is gone forever, so there's an urgency in trying to collect the records before they are lost.

The loss of tropical glaciers is very telling because they're in such sensitive places. Half of the surface of the planet lies between $30^{\circ} \mathrm{N}$ and $30^{\circ} \mathrm{S}$. That's where the heat that drives the climate system is received. It's also

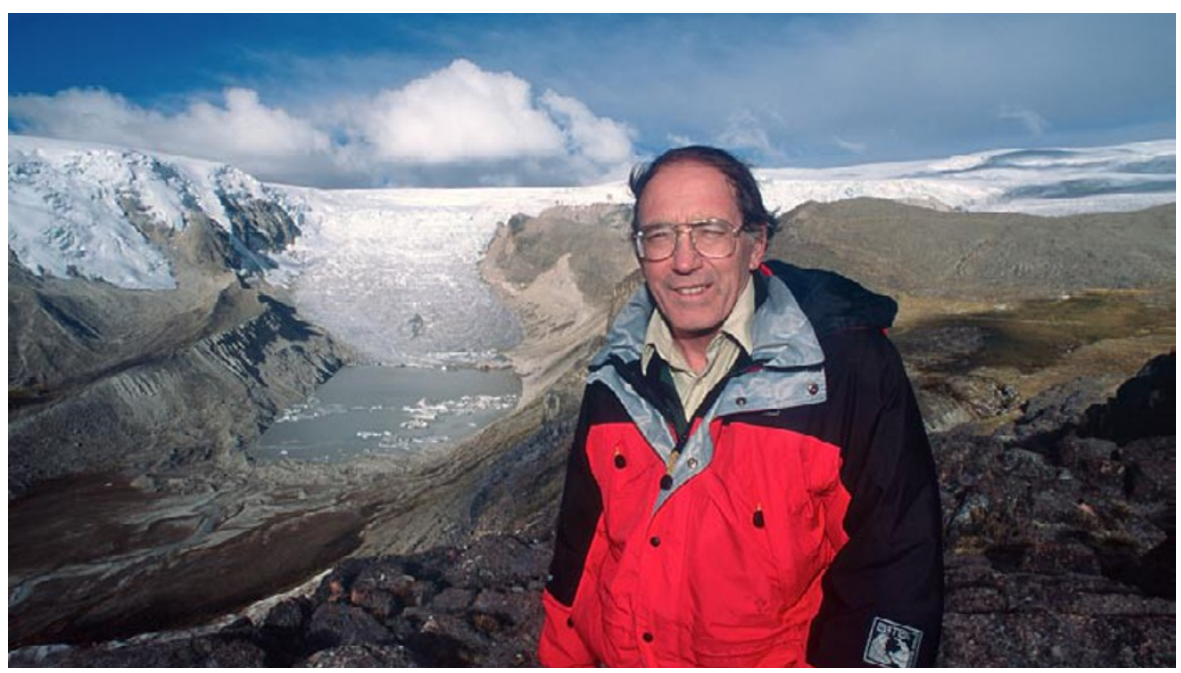

where 70 per cent of the 6.7 billion people on the planet live.

\section{What's the effect on people as these glaciers disappear?}

After this meeting, we're headed to Peru to drill new ice cores at two sites. That country contains 75 per cent of the world's glaciers. Eighty per cent of its population is in the desert on the west coast, and 76 per cent of the electricity comes from hydropower, from streams that are fed by glaciers in the Andes, all of which are retreating. Those changes are impacting the ability to produce hydropower, to irrigate crops in the desert and to provide municipal water supplies.

How can we deal with such changes? One possibility is to build dams to capture the water and do what the glacier does for free. You can think of a glacier as a water tower. It accumulates water in the wet season, when 70-80 per cent of precipitation falls, and in the dry season it melts back and keeps water flowing in the streams. Unfortunately, people live in these river valleys - usually Quechua Indians - as have their ancestors, and there's no way that they will want the valleys to be flooded to construct these dams. There have been riots already, just this past year. So even if you can come up with a solution from afar, there can be problems when you go to implement it on a local level.

In the twenty-first century we human beings face two major problems: how do we get along with each other, and how do we get along with our planet? Of course, our ability to get along with each other is probably going to be tested as we have water shortages and other climate-related impacts on cultures and economies around the planet. So the challenge will be how we can change the way we go about our daily activities to make our future sustainable.

Published online: 9 July 2009

doi:10.1038/climate.2009.66

Anna Barnett is assistant editor and copy editor of Nature Reports Climate Change. 